\title{
Examination of the clinical efficacy of eribulin and trastuzumab in HER2-positive recurrent breast cancer
}

\author{
TAKAYOSHI KIBA ${ }^{1}$, NAO MORII ${ }^{2,3}$, HIROTOSHI TAKAHASHI ${ }^{2}$, SHINJI OZAKI $^{2}$, MISAO ATSUMI ${ }^{4}$, \\ FUMI MASUMOTO $^{4}$, YOSHIMI SHITAKUBO ${ }^{1}$ and HIROYASU YAMASHIRO ${ }^{2,3}$
}

\begin{abstract}
${ }^{1}$ Division of Modern Medical Technology, Institute for Clinical Research; ${ }^{2}$ Department of Breast Surgery, National Hospital Organization Kure Medical Center and Chugoku Cancer Center, Kure, Hiroshima 737-0023; ${ }^{3}$ Department of Breast Surgery, Tenri Hospital, Tenri, Nara 632-8552; ${ }^{4}$ Clinical Trial Management Office, National Hospital Organization

Kure Medical Center and Chugoku Cancer Center, Kure, Hiroshima 737-0023, Japan
\end{abstract}

Received May 5, 2015; Accepted October 26, 2015

\section{DOI: $10.3892 / \mathrm{mco} .2015 .668$}

\begin{abstract}
There are limited studies reported that describe the efficacy of eribulin and trastuzumab in the treatment of recurrent breast cancer. The present study examined the therapeutic efficacy of eribulin and trastuzumab in the treatment of recurrent breast cancer. Between October 2011 and August 2013, 5 recurrent breast cancer patients who were treated with eribulin and trastuzumab were included in the study. The cancer stages in the 5 women who received this regimen were stage IIIB in $1(20 \%)$ and stage IV in $4(80 \%)$ The sites of recurrence were the lung in 3 patients, liver in 2, bone in 1 , brain in 1 , supraclavicular lymph nodes in 1 , infraclavicular lymph nodes in 1 and mediastinal lymph nodes in 1 . The median number of prior treatment regimens was 5 (range, 5-11). Complete response was achieved in 0 patients, 1 achieved partial response, 3 had stable disease, and 1 had progressive disease. The overall response rate was $20 \%$, and the clinical benefit rate was $80 \%$. Patients also reported grade $3 / 4$ neutropenia $(80.0 \%)$. However, hematological toxicity was reversible and manageable. The most common grade $3 / 4$ nonhematological toxicities were fatigue $(20.0 \%)$, peripheral neuropathy $(20.0 \%)$ and appetite loss $(20.0 \%)$. No patients withdrew from treatment, and favorable compliance was achieved in the study. The results indicated that eribulin and trastuzumab have the potential to be one of the drugs for treatment of recurrent breast cancer.
\end{abstract}

Correspondence to: Dr Takayoshi Kiba, Division of Modern Medical Technology, Institute for Clinical Research, National Hospital Organization Kure Medical Center and Chugoku Cancer Center, 3-1 Aoyama-cho, Kure, Hiroshima 737-0023, Japan

E-mail: takkiba@hotmail.com

Abbreviations: ER, estrogen receptor; HER2, human epidermal growth factor receptor 2

Key words: eribulin, trastuzumab, breast cancer

\section{Introduction}

Estrogen receptor (ER)-positive and human epidermal growth factor receptor 2(HER2)-positive disease with metastatic breast cancer remain incurable (1-3). For metastatic breast cancer, anthracycline- and/or taxane-based chemotherapy is used as standard treatment (4); however, the outcome remains a common issue. Therefore, new treatments are required. The patients with overexpression of HER2 may benefit from trastuzumab, and these may perform more efficiently with chemotherapy regimens that contain anthracycline drugs. HER2 overexpression comprises $15-25 \%$ of all breast cancers (5). By contrast, vinca alkaloids, gemcitabine, capecitabine, liposomal anthracyclines and nanoparticle albumin-bound paclitaxel were approved as third-line or later treatment of metastatic breast cancer (6).

Eribulin maculate (E7389) is an analog of the natural marine product, halichondrin $\mathrm{B}$, a nontaxane microtubule dynamics inhibitor extracted from the marine sponge Halichondria okadai, which inhibits microtubule structures via a novel mechanism of action (7). The drug induces an irreversible mitotic block, which leads to cell cycle arrest in the $\mathrm{G}_{2} / \mathrm{M}$ phase and apoptosis (8). It is distinguished mechanistically from other antimicrotubule agents, such as paclitaxel, ixabepilone and vinblastine (9). Additionally, the drug has potent antiproliferative effects against several different types of human cancer cell lines, including breast, prostate, melanoma and colorectal cancer $(10,11)$, and has evolved activity against paclitaxel-resistant cell lines, including those with mutations in $\beta$-tubulin (12). It has also provided a manageable tolerability profile in phase I-II clinical trials and an improvement in overall survival compared with the treatment decided by the physician in a phase III trial (13).

In the present study, eribulin and trastuzumab were administered to 5 patients with recurrent breast cancer between October 2011 and August 2013. The study investigated eribulin and trastuzumab and reports the results obtained.

\section{Patients and methods}

Ethics statement. Only the demographic data of patients were stored in the database in the National Hospital Organization 
Kure Medical Center and Chugoku Cancer Center (Kure, Japan) to enable the retrieval of files manually based on patient codes. All the data were anonymously analysed without individual patient consent due to the retrospective nature of the study. The Review Board Ethics Committee waived the requirement for individual informed consent and approved the study (Approval Number 26-27, date 8/14/14).

Patients. Between October 2011 and August 2013, 5 patients with recurrent breast cancer were included in the study. All the patients received neoadjuvant or adjuvant taxane or antracycline chemotherapy following breast surgery. The mean age of the patients at the time of the eribulin and trastuzumab regimen administration was 70 years (range, 53-76 years) (Table I). The interval between tumor resection and local recurrence varied widely from 1.6 to 31.5 months. The histological type of the primary cancer was invasive ductal carcinoma in 5 patients. Pathological lymph node metastases at the time of surgery were classified as $n 1$ in 2 patients, $n 2$ in 1 and $\mathrm{n} 3$ in 2 . Hormone sensitivity was identified as positive in 2 cases $\left[1\right.$ case of $\mathrm{ER}^{+} /$progesterone receptor $(\mathrm{PgR})^{+}$and 1 case of $\left.\mathrm{ER}^{-} / \mathrm{PgR}^{+}\right]$and negative in 3. Tamoxifen or aromatase inhibitors were postoperatively administered to all 5 patients.

The status of pre-treatment ER and PgR was assessed by immunohistochemistry (IHC), and HER2 status was assessed by either fluorescent in situ hybridization or a validated IHC method, as previously described (14-16). Patients with HER2-receptor overexpression at the $3^{+}$level (PATHWAY ${ }^{\circledR}$ HER2, clone 4B5; Ventana Medical Systems Inc., Tucson, AZ, USA) were immediately eligible for inclusion. When immunostaining was observed in $>1 \%$ of tumor nuclei, the tumor was considered positive for the ER or PgR (16). Breast cancers were classified into five subtypes, as previously described (16).

The cancer stages in the 5 women who received this regimen were stage IIIB in $1(20 \%)$ and stage IV in $4(80 \%)$. The sites of recurrence were the lung in 3 patients, liver in 2 , bone in 1 , brain in 1 , supraclavicular lymph nodes in 1 , infraclavicular lymph nodes in 1 and mediastinal lymph nodes in 1 . The median number of prior treatment regimens was 5 (range, 5-11).

Eribulin mesylate and trastuzumab were administered as previously described $(15,17)$. Concomitant medication that did not interfere with the evaluation of eribulin could be administered, including antiemetics, antidiarrheal therapy, corticosteroids and antihistamines. Granulocyte colony-stimulating factor was allowed according to the American Society of Clinical Oncology guidelines and standard practice, including prophylactic use of growth factors (18).

Patients treated with bisphosphonates or denosumab at study entry could continue treatment. Other antitumor therapies were not allowed. This treatment cycle was repeated as long as the therapeutic effects were observed. The efficacy of eribulin and trastuzumab was assessed from the 2 nd or 3 rd cycle following administration according to the Response Evaluation Criteria in Solid Tumors guidelines (19).

Statistical analysis. Pearson $\chi^{2}$ tests were used to assess differences in overall response rates by group. All statistical analyses were performed using SPSS software, version 19.0 (IBM Corp.,
Table I. Patient characteristics $(n=5)$.

\section{Characteristics}

Patients

Age, median years (range)

$70(53-76)$

Gender, $\mathrm{n}$

Male

0

Female

5

Eastern Cooperative Oncology Group performance status, n (\%)

0

$5(100)$

$\geq 1$

$0(0)$

Pathological lymph node metastases

at the time of surgery, $\mathrm{n}(\%)$

$\mathrm{n} 1$

$\mathrm{n} 2$

n3

Hormone sensitivity, n (\%)

$\mathrm{ER}^{+} / \mathrm{PgR}^{+}$

$\mathrm{ER}^{+} / \mathrm{PgR}^{-}$

$\mathrm{ER}^{-} / \mathrm{PgR}^{+}$

$\mathrm{ER}^{-} / \mathrm{PgR}^{-}$

American Joint Committee on Cancer stage, n (\%)

IIIA

IIIB

IV

Metastases, n (\%)

Lung

Liver

$2(40)$

Bone

$1(20)$

$1(20)$

$1(20)$

Supraclavicular lymph nodes

$1(20)$

Infraclavicular lymph nodes

Mediastinal lymph nodes

$3(60)$

$0(0)$

$1(20)$

4

median (range)

Type of prior treatment regimen, n (\%)

Docetaxel/trastuzumab

Navelbine/trastuzumab

Capecitabine/trastuzumab

Trastuzumab alone

$3(60)$

Paclitaxel/trastuzumab

$2(40)$

Lapatinib/capecitabine

$2(40)$

S1/trastuzumab

$2(40)$

S1/lapatinib/capecitabine

2 (40)

$2(40)$

$2(40)$

Cyclophosphamide/capecitabine/trastuzumab

$2(40)$

Toremifene/trastuzumab

$1(20)$

$1(20)$

$1(20)$

$1(20)$

1 (20) 
Table II. All adverse events $(n=5)$.

Grades, n (\%)

\begin{tabular}{lllll}
\cline { 2 - 4 } Adverse event & 1 & 2 & 3 & 4 \\
\hline Anemia & $1(20)$ & $2(40)$ & $0(0)$ & $0(0)$ \\
Neutropenia & $0(0)$ & $0(0)$ & $2(40)$ & $2(40)$ \\
Nausea & $3(60)$ & $0(0)$ & $0(0)$ & $0(0)$ \\
Fatigue & $2(40)$ & $1(20)$ & $1(20)$ & $0(0)$ \\
Peripheral neuropathy & $1(20)$ & $1(20)$ & $1(20)$ & $0(0)$ \\
Gait disturbance & $0(0)$ & $1(20)$ & $0(0)$ & $0(0)$ \\
Appetite loss & $2(40)$ & $0(0)$ & $1(20)$ & $0(0)$ \\
Stomatitis & $1(20)$ & $1(20)$ & $0(0)$ & $0(0)$ \\
Diarrhea & $2(40)$ & $0(0)$ & $0(0)$ & $0(0)$ \\
Constipation & $2(40)$ & $0(0)$ & $0(0)$ & $0(0)$ \\
& & & & \\
\hline
\end{tabular}

Tokyo, Japan). $\mathrm{P}=0.05$ was considered to indicate a statistically significant difference.

\section{Results}

Patient variables. Among the 5 patients, 0 achieved complete response, 1 achieved partial response, 3 had stable disease, and 1 had progressive disease. The overall response rate was $20 \%$, and the clinical benefit rate was $80 \%$. The mean duration of eribulin and trastuzumab administration was 9 cycles (4-11). The status of hormone sensitivity did not affect the overall response rate $\left(\mathrm{P}=0.33, \chi^{2}\right)$.

Toxicities. All 5 patients were evaluated for toxicity using the Common Terminology Criteria for Adverse Events version 4.0 (http://ctep.cancer.gov/protocolDevelopment/electronic_applications/ctc.htm\#ctc_40). Hematological toxicity was reversible and manageable. Patients reported grade $3 / 4$ neutropenia $(80.0 \%)$ (Table II). Although grade 4 neutropenia occurred, the patients were treated with granulocyte colony-stimulating factors. The most common grade $3 / 4$ nonhematological toxicities were fatigue $(20.0 \%)$, peripheral neuropathy $(20.0 \%)$ and appetite loss $(20.0 \%)$. There were no treatment-related fatalities. As these toxicities were mild, eribulin and trastuzumab dose omission was rare, and the study achieved favorable compliance.

\section{Discussion}

The present study examined the efficacy of eribulin and trastuzumab in recurrent breast cancer. In a multicenter, phase II, single-arm study, 52 patients with recurrent or metastatic HER2-positive breast cancer received first-line eribulin with trastuzumab. The overall response rate was $71.2 \%$ with a median time to first response of 1.3 months; duration of response and progression free survival was 11.1 and 11.6 months, respectively (20). In the present study, the overall response rate was $20 \%$, and the clinical benefit rate was $80 \%$.

The toxicity profile was generally acceptable (Table II). The major toxicity was myelosuppression (the incidence of grade $3 / 4$ toxicity was $80 \%$ for neutropenia), fatigue (the incidence of grade 3 was 20\%), peripheral neuropathy (the incidence of grade 3 was 20\%), and appetite loss (the incidence of grade 3 was $20 \%$ ). Although grade 4 neutropenia occurred, the patients were treated with granulocyte colony-stimulating factors. Treatment-related fatalities were not observed. Consistent with this, the trial was reported by Wilks et al (20), who treated 52 patients with locally recurrent or metastatic HER2-positive breast cancer with eribulin and trastuzumab. The most common grade 3/4 treatment-emergent adverse events were neutropenia in 20 (38.5\%) patients, peripheral neuropathy in $14(26.9 \%$; all grade 3$)$, fatigue in $4(7.7 \%)$ and febrile neutropenia in $4(7.7 \%)$. Grade 3 adverse events included thrombocytopenia (in $28 \%$ of patients), fatigue (in $12 \%$ ), peripheral neuropathy (in 12\%) and neutropenia (in $11 \%$ ), whereas grade 4 events (thrombocytopenia, neutropenia, vomiting, diarrhea and weakness) occurred in 14\% of patients; otherwise, no severe adverse events occurred. The activity of eribulin with trastuzumab appears comparable with that of other combinations currently recommended for metastatic HER2-positive breast cancer (13). Although incidence rates vary, peripheral neuropathy is a common adverse event in patients treated with microtubule-targeted agents occurring in $<30 \%$ of patients (21). Peripheral neuropathy grade $3 / 4$ also occurs frequently in patients treated with eribulin. In the phase 3 EMBRACE trial, 35\% of eribulin-treated patients had neuropathy, however, $<9 \%$ had grade $3 / 4$ neuropathy (13). Wilks et al (20) recently reported that 36 (69.2\%) patients experienced neuropathy, and 14 (26.9\%) experienced grade 3 neuropathy; no grade 4 neuropathy was observed. This higher rate of grade 3 neuropathy was likely due to the prolonged duration of eribulin treatment in this first-line setting.

In conclusion, recent clinical studies and the present study demonstrate that due to the high clinical benefit rate and acceptable safety profile, a combination of eribulin/trastuzumab is an acceptable treatment option for metastatic HER2-positive breast cancer. This may be a reflection of inadequate sample size. The present study is a retrospective study, and therefore, these results should be confirmed in further prospective studies.

\section{Acknowledgements}

The authors would like to thank Mrs. Kanako Tanaka for her excellent research assistance.

\section{References}

1. Ueno M,KibaT,Nishimura T,Kitano T, Yanagihara K, YoshikawaK, Ishiguro $\mathrm{H}$, Teramukai S, Fukushima M, Kato $\mathrm{H}$ and Inamoto T: Changes in survival during the past two decades for breast cancer at the Kyoto university hospital. Eur J Surg Oncol 33: 696-699, 2007.

2. Petrelli F, Cabiddu M, Cazzaniga ME, Cremonesi M and Barni S: Targeted therapies for the treatment of breast cancer in the post-trastuzumab era. Oncologist 13: 373-381, 2008.

3. Beslija S, Bonneterre J, Burstein H, Cocquyt V, Gnant M, Goodwin P, Heinemann V, Jassem J, Köstler WJ, Krainer M, et al: Second consensus on medical treatment of metastatic breast cancer. Ann Oncol 18: 215-225, 2007.

4. Ueno NT, Buzdar AU, Singletary SE, Ames FC, McNeese MD, Holmes FA, Theriault RL, Strom EA, Wasaff BJ, Asmar L, et al: Combined-modality treatment of inflammatory breast carcinoma: Twenty years of experience at M. D. Anderson cancer center. Cancer Chemother Pharmacol 40: 321-329, 1997. 
5. Révillion F, Bonneterre J and Peyrat JP: ERBB2 oncogene in human breast cancer and its clinical significance. Eur J Cancer 34: 791-808, 1998.

6. Muñoz-Couselo E, Pérez-García J and Cortés J: Eribulin mesylate as a microtubule inhibitor for treatment of patients with metastatic breast cancer. Onco Targets Ther 4: 185-192, 2011.

7. Jimeno A: Eribulin: Rediscovering tubulin as an anticancer target. Clin Cancer Res 15: 3903-3905, 2009.

8. Smith JA, Wilson L, Azarenko O, Zhu X, Lewis BM, Littlefield BA and Jordan MA: Eribulin binds at microtubule ends to a single site on tubulin to suppress dynamic instability. Biochemistry 49: 1331-1337, 2010.

9. Huyck TK, Gradishar W, Manuguid F and Kirkpatrick P: Eribulin mesylate. Nat Rev Drug Discov 10: 173-174, 2011.

10. Hamel E: Natural products which interact with tubulin in the vinca domain: Maytansine, rhizoxin, phomopsin A, dolastatins 10 and 15 and halichondrin B. Pharmacol Ther 55: 31-51, 1992.

11. Towle MJ, Salvato KA, Budrow J, Wels BF, Kuznetsov G, Aalfs KK, Welsh S, Zheng W, Seletsky BM, Palme MH, et al: In vitro and in vivo anticancer activities of synthetic macrocyclic ketone analogues of halichondrin B. Cancer Res 61: 1013-1021, 2001.

12. Newman S: Eribulin, a simplified ketone analog of the tubulin inhibitor halichondrin B, for the potential treatment of cancer. Curr Opin Investig Drugs 8: 1057-1066, 2007.

13. Cortes J, O'Shaughnessy J, Loesch D, Blum JL, Vahdat LT, Petrakova K, Chollet P, Manikas A, Diéras V, Delozier T, et al: Eribulin monotherapy versus treatment of physician's choice in patients with metastatic breast cancer (EMBRACE): A phase 3 open-label randomized study. Lancet 377: 914-923, 2011.

14. García-Martínez E, Gil GL, Benito AC, González-Billalabeitia E, Conesa MA, García García T, García-Garre E, Vicente V and Ayala de la Peña F: Tumor-infiltrating immune cell profiles and their change after neoadjuvant chemotherapy predict response and prognosis of breast cancer. Breast Cancer Res 16: 488, 2014.

15. Ishida T, Kiba T, Takeda M, Matsuyama K, Teramukai S, Ishiwata R, Masuda N, Takatsuka Y, Noguchi S, Ishioka C, et al: Phase II study of capecitabine and trastuzumab combination chemotherapy in patients with HER2 overexpressing metastatic breast cancers resistant to both anthracyclines and taxanes. Cancer Chemother Pharmacol 64: 361-369, 2009.
16. Kiba T, Morii N, Takahashi H, Ozaki S, Atsumi M, Masumoto F and Yamashiro $\mathrm{H}$ : Pathological response rate in hormone-positive breast cancer patients treated with neoadjuvant FEC and triweekly docetaxel: A case series. Breast Cancer (Dove Med Press) 7: 245-250, 2015.

17. McIntyre K, O'Shaughnessy J, Schwartzberg L, Glück S, Berrak E, Song JX, Cox D and Vahdat LT: Phase 2 study of eribulin mesylate as first-line therapy for locally recurrent or metastatic human epidermal growth factor receptor 2-negative breast cancer. Breast Cancer Res Treat 146: 321-328, 2014.

18. Smith TJ, Khatcheressian J, Lyman GH, Ozer H, Armitage JO, Balducci L, Bennett CL, Cantor SB, Crawford J, Cross SJ, et al: 2006 update of recommendations for the use of white blood cell growth factors: An evidence-based clinical practice guideline. J Clin Oncol 24: 3187-3205, 2006.

19. Therasse P, Arbuck SG, Eisenhauer EA, Wanders J, Kaplan RS, Rubinstein L, Verweij J, Van Glabbeke M, van Oosterom AT, Christian MC and Gwyther SG: New guidelines to evaluate the response to treatment in solid tumors. European organization for research and treatment of cancer, national cancer institute of the united states, national cancer institute of Canada. J Natl Cancer Inst 92: 205-216, 2000.

20. Wilks S, Puhalla S, O'Shaughnessy J, Schwartzberg L, Berrak E, Song J, Cox D and Vahdat L: Phase 2, multicenter, single-arm study of eribulin mesylate with trastuzumab as first-Line therapy for locally recurrent or metastatic HER2-positive breast cancer. Clin Breast Cancer 14: 405-412, 2014.

21. Lee JJ and Swain SM: Peripheral neuropathy induced by microtubule-stabilizing agents. J Clin Oncol 24: 1633-1642, 2006. 